\title{
Eficiência de Utilização da Energia Metabolizável para Mantença e Ganho de Peso e Exigências de Energia Metabolizável e de Nutrientes Digestíveis Totais de Bovinos F1 Limousin x Nelore Não-Castrados 1
}

\section{Cristina Mattos Veloso ${ }^{2}$, Sebastião de Campos Valadares Filho ${ }^{3}$, Antonio Gesuladi Júnior 4 , Fabiano Ferreira da Silva ${ }^{2}$, Mário Fonseca Paulino ${ }^{3}$, Rilene Ferreira Diniz Valadares ${ }^{5}$, Paulo Roberto Cecon ${ }^{6}$, Pedro Veiga Rodrigues Paulino ${ }^{7}$}

\begin{abstract}
RESUMO - Foram utilizados 50 novilhos F1 Limousin x Nelore inteiros, alocados em dez tratamentos, com cinco níveis de concentrado $(25 ; 37,5 ; 50 ; 62,5 ;$ e $75 \%)$ e duas formas de balanceamento protéico da dieta (uma isoprotéica com $12 \%$ de proteína bruta [PB] e outra variando proteína com energia). O consumo de matéria seca (MS) necessário para manter o equilíbrio de energia foi calculado dividindo-se o consumo de energia metabolizável (EM) necessário para mantença $(112,89 \mathrm{kcal} / \mathrm{PCVZ}$, 75$)$, pela concentração de EM ( $\mathrm{kcal} / \mathrm{kg}$ de MS) da dieta, em cada tratamento. A concentração de energia líquida (EL) para mantença de cada ração foi obtida dividindo-se a produção de calor em jejum, $76,36 \mathrm{kcal} / \mathrm{kgPCVZ}{ }^{0,75}$, pelo consumo de MS para manter o equilíbrio de energia, expresso em g de $\mathrm{MS} / \mathrm{kg} \mathrm{PCVZ}{ }^{0,75}$. A concentração de EL para ganho foi calculada dividindo-se a energia retida por dia, em $\mathrm{kcal} / \mathrm{kg} \mathrm{PCVZ}^{0,75}$, pelo consumo de MS acima das necessidades de mantença, expresso em g MS $/ \mathrm{kg} \mathrm{PCVZ}^{0,75}$. As eficiências de utilização da EM para mantença $\left(\mathrm{k}_{\mathrm{m}}\right)$ e ganho de peso $\left(\mathrm{k}_{\mathrm{f}}\right)$ foram estimadas a partir da relação entre os teores de energia líquida, para mantença ou ganho, respectivamente, em função da EM da dieta, e a $\mathrm{k}_{\mathrm{f}}$ também foi estimada como o coeficiente de regressão linear entre a energia retida e o consumo de EM, juntamente com os dados relativos aos animais designados de mantença. A eficiência de utilização da EM para mantença foi calculada em 0,68 e a eficiência de utilização da EM para ganho, em 0,$52 ; 0,50 ; 0,55 ; 0,60$; e 0,50, respectivamente, para as dietas com 1,93; 2,09; 2,28; 2,42; e 2,70 Mcal de EM/kg de MS, obtidas para os níveis de 25; 37,5; 50; 62,5; e 75\% de concentrado. As exigências de EM, ED e NDT para mantença, calculadas, foram 112,3 e $137,0 \mathrm{kcal} / \mathrm{kg} \mathrm{PCVZ}^{0,75}$ e $31,1 \mathrm{~g} / \mathrm{kg} \mathrm{PCVZ}$, 75 , respectivamente.
\end{abstract}

Palavras-chave: eficiência de utilização, energia metabolizável, mestiços, níveis de concentrado, requisitos

\section{Efficiency of Metabolizable Energy Utilization for Maintenance and Weight Gain and Metabolizable Energy and Total Digestible Nutrients Requirements of F1 Limousin $x$ Nellore Bulls}

\begin{abstract}
Fifty F1 Limousin x Nellore bulls were allocated in ten treatments, with five concentrate levels (25, 37.5, 50, 62.5 , and $75 \%$ ) and two diet protein balance methods (one isoprotein and the other changing protein as diet energy changed). Dry matter intake (DMI) required to maintain the energy balance was calculated dividing the metabolizable energy intake (MEI) required for maintenance $\left(112.89 \mathrm{kcal} / \mathrm{kg} \mathrm{EBW}^{0.75}\right)$, by diet ME concentration $(\mathrm{kcal} / \mathrm{kg}$ of $\mathrm{DM})$, in each treatment. The net energy concentration for maintenance $(\mathrm{NEm})$ of each ration was obtained by dividing heat production in fasting $(76.36 \mathrm{kcal} / \mathrm{kg} \mathrm{EBW}$. by DMI to maintain energy balance, expressed in $\mathrm{g}$ of $\mathrm{DM} / \mathrm{kg} \mathrm{EBW}^{0.75}$. NEg concentration was calculated by dividing the energy retained per day $\left(\mathrm{kcal}^{\mathrm{kg}} \mathrm{EBW}^{0.75}\right)$ by the DMI above the maintenance requirements, expressed in $\mathrm{g} \mathrm{DM}^{\mathrm{kg}} \mathrm{EBW}^{0.75}$. The efficiencies of utilization of ME $(\mathrm{k})$ for maintenance $\left(\mathrm{k}_{\mathrm{m}}\right)$ and for weight gain $\left(\mathrm{k}_{\mathrm{f}}\right)$ were estimated from the relationship between the net energy concentration, for maintenance or gain, respectively, as function of the ME of the diet, and $\mathrm{k}_{\mathrm{f}}$ was also calculated as the linear regression coefficient between retained energy and MEI, together with the data of the maintenance animals. The $\mathrm{k}$ value for maintenance $\left(\mathrm{k}_{\mathrm{m}}\right)$ was 0,68 and for gain $\left(\mathrm{k}_{\mathrm{f}}\right)$ were $0.52 ; 0.50 ; 0.55 ; 0.60$ and 0.50 , respectively, for diets with $1.93 ; 2.09 ; 2.28$; 2.42 and $2.70 \mathrm{Mcal}$ of ME/kg of DM, obtained for concentrate levels of $25 ; 37.5 ; 50 ; 62.5$ and $75 \%$. ME, DE and TDN maintenance requirements were 112.3 and $137.0 \mathrm{kcal} / \mathrm{kg} \mathrm{EBW}^{0.75}$, and $31.1 \mathrm{~g} / \mathrm{kg} \mathrm{EBW}^{0.75}$, respectively.
\end{abstract}

Key Words: concentrate levels, crossbred, efficiency of utilization, metabolizable energy, requirements

\footnotetext{
${ }_{1}^{1}$ Parte da tese de Doutorado em Zootecnia apresentada pela primeira autora à UFV. Financiada pela FAPEMIG

2 Professor(a) do curso de Zootecnia - UESB - Itapetinga, BA. E.mail: cmveloso@uesb.br; ffsilva@uesb.br

3 Professor do Departamento de Zootecnia - UFV - Viçosa, MG. Bolsista do CNPq.E.mail: svcfilho@mail.ufv.br; mpaulino@mail.ufv.br

${ }^{4}$ Estudante de Doutorado em Zootecnia - UFV - Viçosa, MG. E.mail: anaton@vicosa.com.br

5 Professora do Departamento de Medicina Veterinária - UFV - Viçosa, MG. Bolsista do CNPq. E.mail: rilene@mail.ufv.br

${ }^{6}$ Professor do Departamento de Matemática - UFV - Viçosa, MG. E.mail: cecon@dpi.ufv.br

${ }^{7}$ Mestrando em Zootecnia UFV - Viçosa, MG. E.mail: eg35439@correio.ufv.br
} 


\section{Introdução}

A maioria das pesquisas brasileiras sobre exigências nutricionais de bovinos não apresenta fatores para a conversão das exigências líquidas em exigências dietéticas, sendo utilizados valores oriundos de tabelas elaboradas em outros países (Boin, 1995; Fontes, 1995; Valadares Filho, 1995).

A partir do conhecimento das exigências líquidas e levando-se em consideração os fatores de eficiência de utilização da energia do alimento para mantença e ganho, são obtidas as exigências dietéticas. Portanto, o conhecimento da eficiência de utilização da energia metabolizável (k) da dieta é necessário para a determinação das exigências de EM e de nutrientes digestíveis totais (NDT). No entanto, Silva \& Leão (1979) consideram as exigências energéticas dos animais as mais difíceis de serem determinadas, pois o valor de $\mathrm{k}$ é variável para os diferentes processos fisiológicos, além das exigências sofrerem interferências do clima, trabalho muscular e, principalmente, da concentração de EM da dieta.

As estimativas de $\mathrm{k}$ para mantença $(\mathrm{km})$ e ganho (kf) são obtidas a partir de equações não-lineares entre a energia líquida de mantença (ELm) e a EM da dieta e entre a energia líquida para ganho (ELg) e a EM da dieta, respectivamente (Garrett, 1980a,b). A kf também pode ser estimada como o coeficiente de regressão linear entre a energia retida (ER) e o consumo de EM (CEM), segundo o NRC (1996) e Ferrell \& Jenkins (1998a,b).

Os valores de $\mathrm{k}$ da ração não estão bem estabelecidos para ruminantes. O NRC (1984) mostra valores de k para mantença variando de 57,6 a $68,6 \%$ e para ganho, de 29,6 a 47,3\%, conforme os teores de EM da ração. Garrett (1980a) relatou que, segundo resultados experimentais, a eficiência de utilização da EM para a síntese protéica varia de 10 a $40 \%$, enquanto para a síntese de gordura, de 60 a $80 \%$.

De acordo com Rattray \& Joyce (1976), ganhos associados com alta deposição de gordura foram energeticamente mais eficientes, porém menos eficientes em relação à conversão de alimentos em peso vivo (PV), quando comparados a ganhos com pequena deposição de gordura. Isto ocorre porque o tecido adiposo, no qual ocorre grande parte do aumento de PV, contém teores mais elevados de matéria seca (Lana, 1991) que os músculos (80 vs 30\%, aproximadamente).

As variações no balanço da energia são dependentes do nível de ingestão de alimentos, que é influenciado por interações entre os alimentos, denominadas efeito associativo. A eficiência de utilização da energia ingerida tende a ser maior para dietas concentradas, quando comparadas aos volumosos, devido à menor exigência líquida para mantença (ARC, 1980). A adição de concentrado a dietas ricas em volumosos aumenta parcialmente os valores de $\mathrm{k}$ para mantença e ganho (NRC, 1984), em virtude da redução da produção de metano, da ruminação e do incremento calórico. Também, alimentos volumosos de melhor qualidade são mais eficientes que os de pior qualidade (Van Soest, 1994).

Diferenças nas taxas metabólicas dos vários órgãos e vísceras também podem influenciar a utilização da energia. Ferrell (1988) relataram que os tecidos viscerais, embora compreendam pequena porção do peso corporal $(6,2 \%)$, consomem, aproximadamente, $50 \%$ da energia para mantença. Por outro lado, o tecido muscular, que constitui cerca de $41 \%$ da massa corporal, consome apenas $23 \%$ do total da energia requerida para mantença.

O objetivo deste trabalho foi determinar a eficiência de utilização da energia metabolizável para ganho de peso e as exigências de energia metabolizável e de nutrientes digestíveis totais para bovinos F1 Limousin $\mathrm{x}$ Nelore, não-castrados, alimentados com rações contendo diferentes níveis de concentrado.

\section{Material e Métodos}

O experimento foi conduzido no Departamento de Zootecnia da Universidade Federal de Viçosa, em Viçosa-MG. Foram utilizados 50 novilhos F1 Limousin $\mathrm{x}$ Nelore, não-castrados, com peso vivo médio inicial de $330 \mathrm{~kg}$. Cinco novilhos foram abatidos após o período de adaptação de 45 dias (grupo referência), servindo de referência nos estudos subseqüentes. Cinco novilhos foram alimentados com uma dieta contendo feno de capim-Coastcross (Cynodon dactylon) (grupo mantença), para atender às exigências energéticas para mantença. Os 40 animais restantes foram pesados e distribuídos em dez tratamentos, com cinco níveis de concentrado nas dietas, quais sejam: $25 ; 37,5 ; 50 ; 62,5$; e $75 \%$ e duas formas de balanceamento protéico da dieta (uma isoprotéica com, aproximadamente, $12 \%$ de proteína bruta e outra variando proteína e energia), em esquema fatorial 5 × 2 (cinco níveis de concentrado x duas formas de balanceamento protéico), em um delineamento inteiramente casualizado, com quatro repeti-

R. Bras. Zootec., v.31, n.3, p.1286-1293, 2002 
ções por tratamento. O volumoso consistiu de feno de capim-Coastcross (Cynodon dactylon). Em cada grupo, quatro animais foram alimentados com rações formuladas com o intuito de serem isoprotéicas, com, aproximadamente, $12 \%$ de PB na matéria seca (MS), de acordo com o NRC (1996), nível um, e quatro animais foram alimentados com rações formuladas de acordo com o NRC (1996), nível dois, que não foram isoprotéicas. A composição bromatológica das dietas encontra-se na Tabela 1.

$\mathrm{O}$ alimento foi fornecido à vontade, uma vez ao dia, e ajustado de forma a manter sobras entre 5 e $10 \%$ do fornecido, com água permanentemente à disposição dos animais. Foi realizada uma pesagem dos animais no início do experimento e, periodicamente, a cada 28 dias. À medida que um animal se aproximava do peso de abate preestabelecido, $500 \mathrm{~kg}$, era pesado a intervalos menores. Antes do abate, os animais foram submetidos a um jejum de 16 horas. Após o abate, o trato gastrintestinal foi esvaziado, lavado, pesado e seu peso foi somado aos dos órgãos e demais partes do corpo (carcaça, cabeça, couro, cauda, pés e sangue) para determinação do peso de corpo vazio (PCVZ).

As concentrações de energia líquida das dietas foram calculadas segundo Harris (1970). Os valores de EM das dietas foram calculados considerando-se que $1 \mathrm{~kg}$ de NDT é igual a 4,409 Mcal de ED e $1 \mathrm{Mcal}$ de ED, a 0,82 Mcal de EM (Harris, 1970).

$\mathrm{O}$ consumo de MS necessário para manter o equilíbrio de energia foi calculado dividindo-se o consumo diário de EM necessário para mantença, ou seja, o ponto no qual a produção diária de calor (PC) foi igual ao CEM $\left(112,89 \mathrm{kcal} / \mathrm{kg} \mathrm{PCVZ}{ }^{0,75}\right.$ ) (Veloso et al., 2002), pela concentração de EM ( $\mathrm{kcal} / \mathrm{kg}$ de MS) da dieta, em cada tratamento.

A concentração de energia líquida para mantença (ELm), de cada ração, foi obtida dividindo-se a produção de calor em jejum, 76,36 kcal $/ \mathrm{kgPCVZ}^{0,75} / \mathrm{dia}$ (Veloso et al., 2001), pelo consumo de MS para manter o equilíbrio de energia, expresso em $\mathrm{g}$ de $\mathrm{MS} / \mathrm{kg} \mathrm{PCVZ}^{0,75}$. O consumo de MS acima das necessidades de mantença foi obtido subtraindo-se do consumo total de MS (g MS/kg PCVZ ${ }^{0,75}$ ), o consumo

Tabela 1 - Teores médios de matéria seca (MS), matéria orgânica (MO), proteína bruta (PB), extrato etéreo (EE), carboidratos totais $(\mathrm{CHO})$, fibra em detergente neutro (FDN), carboidratos não fibrosos (CNF), nutrientes digestíveis totais (NDT), cálcio $(\mathrm{Ca})$ e fósforo $(\mathrm{P})$ das dietas experimentais

Table 1 - Average contents of dry matter (DM), organic matter (OM), crude protein (CP), ether extract (EE), total carbohydrates (CHO), neutral detergent fiber (NDF), non fiber carbohydrates (NFC), total digestible nutrients (TDN), calcium (Ca) and phosphorus $(P)$ of experimental diets

\begin{tabular}{|c|c|c|c|c|c|c|c|c|c|c|}
\hline \multirow{2}{*}{$\begin{array}{l}\text { Níveis de concentrado na dieta }(\%) \\
\text { Concentrate levels in the diet (\%) } \\
\text { Balanceamento protéico } \\
\text { Protein balance }\end{array}$} & \multicolumn{2}{|c|}{25} & \multicolumn{2}{|c|}{37,5} & \multicolumn{2}{|c|}{50} & \multicolumn{2}{|c|}{62,5} & \multicolumn{2}{|c|}{75} \\
\hline & 1 & 2 & 1 & 2 & 1 & 2 & 1 & 2 & 1 & 2 \\
\hline $\begin{array}{l}\mathrm{MS}, \% \\
D M\end{array}$ & 90,08 & 90,05 & 90,34 & 90,06 & 90,01 & 89,09 & 90,09 & 89,47 & 90,45 & 85,72 \\
\hline $\begin{array}{l}\mathrm{MO}^{1} \\
O M\end{array}$ & 94,73 & 94,83 & 95,25 & 95,28 & 95,74 & 95,53 & 95,94 & 95,96 & 96,40 & 96,23 \\
\hline $\begin{array}{l}\mathrm{PB}^{1} \\
C P\end{array}$ & 11,34 & 10,68 & 11,33 & 11,29 & 12,22 & 13,39 & 12,62 & 14,16 & 14,04 & 16,40 \\
\hline $\begin{array}{l}\mathrm{EE}^{1} \\
\mathrm{CHO}^{1} \\
\mathrm{FDN}^{1,2}\end{array}$ & $\begin{array}{r}1,11 \\
82,29 \\
68,51\end{array}$ & $\begin{array}{r}1,16 \\
82,99 \\
68,40\end{array}$ & $\begin{array}{r}1,34 \\
82,58 \\
61,81\end{array}$ & $\begin{array}{r}1,46 \\
82,53 \\
61,60\end{array}$ & $\begin{array}{r}1,88 \\
81,64 \\
54,12\end{array}$ & $\begin{array}{r}1,56 \\
80,58 \\
54,61\end{array}$ & $\begin{array}{r}2,29 \\
81,03 \\
45,59\end{array}$ & $\begin{array}{r}2,72 \\
79,08 \\
45,55\end{array}$ & $\begin{array}{r}2,54 \\
79,82 \\
34,74\end{array}$ & $\begin{array}{r}1,09 \\
78,74 \\
37,09\end{array}$ \\
\hline $\begin{array}{l}N D F \\
\mathrm{CNF}^{1} \\
N F C\end{array}$ & 13,78 & 14,59 & 20,77 & 20,93 & 27,52 & 25,97 & 35,44 & 33,53 & 45,09 & 41,65 \\
\hline $\begin{array}{l}\text { NDT } \\
T D N\end{array}$ & $55,87^{4}$ & $51,15^{3}$ & $59,55^{4}$ & $56,13^{3}$ & $67,17^{4}$ & $58,78^{3}$ & $66,97^{4}$ & $66,88^{3}$ & $76,40^{4}$ & $72,76^{3}$ \\
\hline $\begin{array}{l}\mathrm{Ca}^{1} \\
\mathrm{P}^{1}\end{array}$ & $\begin{array}{l}1,04 \\
0,23\end{array}$ & $\begin{array}{l}1,03 \\
0,23\end{array}$ & $\begin{array}{l}1,05 \\
0,24\end{array}$ & $\begin{array}{l}1,04 \\
0,23\end{array}$ & $\begin{array}{l}1,05 \\
0,24\end{array}$ & $\begin{array}{l}1,06 \\
0,27\end{array}$ & $\begin{array}{l}1,09 \\
0,39\end{array}$ & $\begin{array}{l}1,09 \\
0,26\end{array}$ & $\begin{array}{l}1,07 \\
0,20\end{array}$ & $\begin{array}{l}1,20 \\
0,28\end{array}$ \\
\hline
\end{tabular}

1 - Isoprotéica (Isoprotein).

2 - Proteína variável (Variable protein).

${ }^{1}$ Porcentagem na MS (DM percentage).

2 FDN corrigida para proteína e cinzas (NDF corrected for protein and ash).

${ }^{3}$ Dias et al. (2000).

${ }^{4}$ Cardoso et al. (2000).

R. Bras. Zootec., v.31, n.3, p.1286-1293, 2002 
de MS suficiente para o equilíbrio de energia (g MS $/ \mathrm{kg}$ $\mathrm{PCVZ}^{0,75}$ ), para cada ração. A concentração de ELg foi calculada dividindo-se a ER por dia, em $\mathrm{kcal} / \mathrm{kg}$ $\mathrm{PCVZ}^{0,75}$, pelo consumo de MS acima das necessidades de mantença, expresso em g MS/kg PCVZ ${ }^{0,75}$.

$\mathrm{O}$ valor de $\mathrm{k}$ para mantença $(\mathrm{km})$ foi estimado a partir da relação entre o teor de energia líquida para mantença, em função da EM da dieta, segundo Garrett (1980b). O valor de k para ganho (kf) foi estimado como o coeficiente de regressão linear entre a ER $(\mathrm{kcal} / \mathrm{kg}$ $\left.\mathrm{PCVZ}^{0,75}\right)$ e o CEM (kcal/kg PCVZ $\left.{ }^{0,75}\right)$, para os animais de cada tratamento, segundo o NRC (1996) e Ferrell \& Jenkins (1998a,b), juntamente com os dados relativos aos animais alimentados em nível de mantença.

As exigências de EM para mantença e ganho foram obtidas pelas relações entre as exigências líquidas e os respectivos k, estimados segundo Garrett (1980b). As exigências de NDT foram calculadas dividindo-se as exigências de EM por 0,82, obtendo-se as exigências de ED e, posteriormente, dividindo-se as exigências de ED por 4,409.

As exigências para ganho de $1 \mathrm{~kg}$ de $\mathrm{PCVZ}$ foram multiplicadas pelo fator 1,02 para se obterem as exigências líquidas para ganho de $1 \mathrm{~kg}$ de PV, conforme relação entre ganho de peso de corpo vazio (GPCVZ) e ganho de PV (Veloso et al., 2002).

As determinações de MS, matéria orgânica (MO), nitrogênio total, extrato etéreo (EE), fibra em detergente neutro (FDN) e macroelementos minerais ( $\mathrm{Ca}$ e P) foram realizadas conforme técnicas descritas por Silva (1990), sendo que a PB foi obtida pelo produto entre o teor de nitrogênio total e o fator 6,25. A solução mineral para determinação dos macroelementos minerais foi preparada por via úmida (Silva, 1990). Após as devidas diluições, o teor de P foi determinado por colorimetria e o de $\mathrm{Ca}$, em espectrofotômetro de absorção atômica. Os carboidratos não-fibrosos (CNF) foram obtidos pela relação $100-(\% \mathrm{~PB}+\% \mathrm{FDN}+\% \mathrm{EE}+\%$ Cinzas $)$, conforme recomendações de Hall (2001). Os valores de NDT das dietas foram obtidos por ensaio de digestibilidade, de acordo com Cardoso et al. (2000) e Dias et al. (2000), que utilizaram animais e dietas semelhantes aos do presente experimento.

\section{Resultados e Discussão}

Na Tabela 2, são apresentados os teores de NDT, as concentrações de EM das dietas e os valores calculados de ELm e ELg, além da km calculada, e das estimativas das $\mathrm{k}_{\mathrm{f}}$, segundo Garrett (1980b) e conforme o NRC (1996) e Ferrell \& Jenkins (1998a,b).

Os valores de ELm e ELg encontrados para dietas com concentrações de EM próximas de 2,0 e

Tabela 2 - Teores de nutrientes digestíveis totais (NDT), concentrações de energia metabolizável (EM), energia líquida para mantença $(E L m)$ e energia líquida para ganho (ELg), e eficiências de utilização da energia metabolizável, calculada para mantença $\left(\mathrm{k}_{\mathrm{m}}\right)$ e calculada e estimada para ganho de peso $\left(\mathrm{k}_{\mathrm{f}}\right)$, em função dos níveis de concentrado na dieta

Table 2 - Total digestible nutrients (TDN), metabolizable energy (ME), net energy for maintenance (NEm) and net energy for gain (NEg) and efficiency of utilization of metabolizable energy, calculated for maintenance and calculated and estimated for weight gain, as function of concentrate levels in the diet

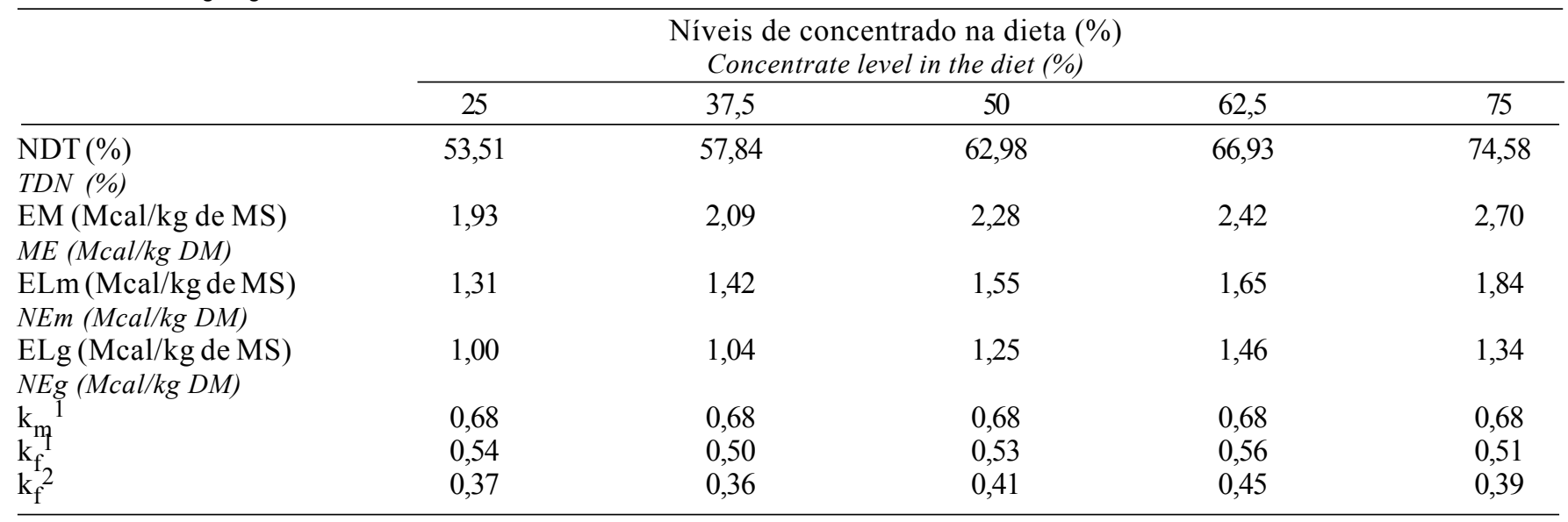

${ }_{1}^{1}$ Calculada utilizando-se os dados do presente trabalho, segundo Garrett (1980b).

2 Estimada segundo o NRC (1996) e Ferrell \& Jenkins (1998a,b), utilizando-se os dados do presente trabalho.

1 Calculated using data of this work, according to Garrett (1980b).

2 Estimated according to NRC (1996) and Ferrell \& Jenkins (1998a,b), using data of this work.

R. Bras. Zootec., v.31, n.3, p.1286-1293, 2002 
2,4 Mcal/kg de MS, 1,31 e 1,64 Mcal/kg de MS para ELm e 1,00 e 1,46 Mcal/kg de MS para ELg foram maiores, especialmente os de ELg, que os estimados por meio das equações de Garrett (1980a), recomendadas pelo NRC (1996), quais sejam:

$$
\begin{gathered}
\text { ELm }(\mathrm{Mcal} / \mathrm{kg} \mathrm{MS})=-1,12+1,37 \mathrm{EM}-0,138 \\
\mathrm{EM}^{2}+0,0105 \mathrm{EM}^{3} \\
\mathrm{ELg}(\mathrm{Mcal} / \mathrm{kg} \mathrm{MS})=-1,65+1,42 \mathrm{EM}-0,174 \\
\mathrm{EM}^{2}+0,0122 \mathrm{EM}^{3}
\end{gathered}
$$

Tal diferença pode ser devida à dieta, pois Garrett (1980a) compilou dados obtidos com a utilização de gramíneas e leguminosas de clima temperado, que possuem maior concentração de EM que as tropicais. Ao extrapolar para o nível de EM de 2,0 a 2,4 Mcal $/ \mathrm{kg}$ MS, comumente encontrado para forrageiras tropicais e mais improvável para forrageiras temperadas, estas apresentaram menores valores de ELm e ELg.

Utilizando tais equações, para rações com teores de EM de 2,0 e 2,4 Mcal $/ \mathrm{kg}$ de MS, a ELm estimada é de 1,15 e $1,52 \mathrm{Mcal} / \mathrm{kg}$ de MS e a ELg, de 0,59 e $0,92 \mathrm{Mcal} / \mathrm{kg}$ de MS, respectivamente. Da mesma forma, Ferreira et al. (1999), trabalhando com animais F1 Simental x Nelore, também encontraram, para uma dieta com 2,43 Mcal de EM/kg de MS, menores concentrações de $\operatorname{ELm}(1,43 \mathrm{Mcal} / \mathrm{kg}$ de MS) e ELg (0,90 Mcal/kg de MS). A $\mathrm{k}_{\mathrm{m}}$ estimada para uma dieta com 2,4 Mcal de EM/kg de MS, segundo Garrett (1980a), seria de 63,3\%, ligeiramente inferior à obtida no presente trabalho e bem próxima à encontrada por Silva et al. (2001), de 63\%.

As equações que geraram os resultados para a estimativa das $\mathrm{k}_{\mathrm{f}}$, representadas pelos coeficientes de regressão das relações lineares entre a ER (Y) e o CEM (X), para os animais de cada tratamento (25; 37,$5 ; 50 ; 62,5$; e $75 \%$ de concentrado), conforme o NRC (1996) e Ferrell \& Jenkins (1998a,b), encontram-se na Tabela 3.

As $\mathrm{k}_{\mathrm{f}}$ estimadas a partir das equações de regressão entre a ER e o CEM apresentaram valores inferiores às $\mathrm{k}_{\mathrm{f}}$ calculadas segundo Garrett (1980b), mas ambas as formas foram superiores aos valores encontrados por Ferreira et al. (1999), oferecendo dietas com os mesmos níveis de concentrado e com EM variando de 2,3 a $2,7 \mathrm{Mcal} / \mathrm{kg}$ MS, a animais F1 Simental x Nelore, exceto para a dieta contendo $75 \%$ de concentrado.

A equação ajustada, relacionando a concentração de ELg (Y), em função da concentração de EM das dietas do presente trabalho, segundo Garrett (1980b), está apresentada na Figura 1. Os valores estimados para $\mathrm{k}_{\mathrm{f}}\left(\mathrm{k}_{\mathrm{f}}{ }^{1}\right.$, Tabela 2$)$ foram determinados
Tabela 3 - Equações de regressão linear entre a energia retida $(\hat{Y})$ e o consumo de energia metabolizável $(X)$, em função dos níveis de concentrado na dieta, e os respectivos coeficientes de determinação $\left(r^{2}\right)$

Table 3 - Linear regression equation between the retained energy $(\hat{Y})$ and metabolizable energy intake $(X)$, as function of concentrate levels in the diet, and the respective determination coefficients $\left(r^{2}\right)$

\begin{tabular}{ccc}
\hline $\begin{array}{c}\text { Níveis de concentrado } \\
\text { Concentrate levels }\end{array}$ & $\begin{array}{c}\text { Equações de regressão } \\
\text { Regression equations }\end{array}$ & $\mathrm{r}^{2}$ \\
\hline 25 & $\hat{\mathrm{Y}}=-2,47623+0,366422 \mathrm{X}$ & 0,79 \\
37,5 & $\hat{\mathrm{Y}}=-2,37030+0,357893 \mathrm{X}$ & 0,89 \\
50 & $\hat{\mathrm{Y}}=-2,79704+0,413828 \mathrm{X}$ & 0,96 \\
62,5 & $\hat{\mathrm{Y}}=-3,00176+0,448773 \mathrm{X}$ & 0,91 \\
75 & $\hat{\mathrm{Y}}=-2,69502+0,393569 \mathrm{X}$ & 0,96
\end{tabular}

a partir da relação entre a ELg, estimada pela referida equação, e as concentrações de EM das dietas.

As exigências de EM, ED e NDT para mantença, para diferentes pesos vivos (PV) e de corpo vazio (PCVZ, calculado pela correlação entre o PCVZ e o $\mathrm{PV}$ dos 40 animais mantidos no experimento, utilizando-se a relação: $P C V Z=P V \times$ 0,8968), são demonstradas na Tabela 4, na qual são observados aumentos

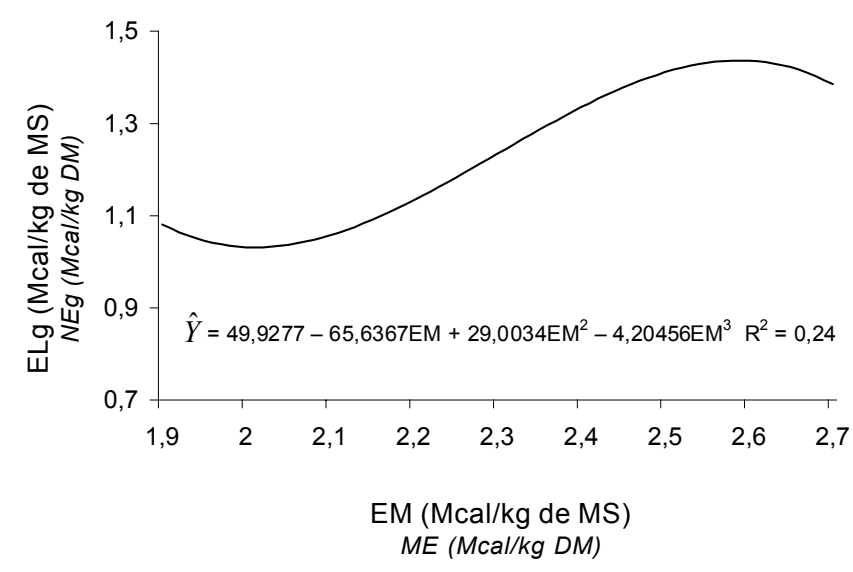

Figura 1 - Estimativa da energia líquida de ganho (ELg), em função da concentração de energia metabolizável (EM) das dietas, expressas em $\mathrm{Mcal} / \mathrm{kg}$ de MS.

Figure 1 - Estimate of net energy for gain (NEg), in function of metabolizable energy (ME) concentration of diets, express in Mcal/kg DM. 
à medida que o peso corporal se eleva, apresentando a mesma tendência das exigências líquidas de energia para mantença (Veloso et al., 2001).

Considerando-se a $\mathrm{k}_{\mathrm{m}}$ obtida de 0,68 e o valor de $76,36 \mathrm{kcal} / \mathrm{kgPCVZ}^{0,75}$ como exigência de energia líquida para mantença (Veloso et al., 2002), a exigência de EM para mantença seria de $112,3 \mathrm{kcal} /$ PCVZ ${ }^{0,75}$; a de ED, $137,0 \mathrm{kcal} / \mathrm{PCVZ}^{0,75}$; e a de NDT, 31,1 g/PCVZ ${ }^{0,75}$, valores inferiores aos encontrados por Ferreira et al. (1999), com bovinos F1 Simental x Nelore não-castrados, e por Silva et al. (2001), com Nelore.

$\mathrm{Na}$ Tabela 5, são apresentadas as estimativas das exigências de ELg, em Mcal por kg de ganho de peso corporal vazio (Mcal/kg GPCVZ), de EM para ganho de peso, em Mcal por kg de ganho de peso vivo em jejum (Mcal/kg GPVJ), e de NDT, em $\mathrm{kg} / \mathrm{kg}$ de GPVJ, utilizando-se a relação entre as exigências líquidas estimadas para os dados em conjunto, por Veloso et al. (2001) $(\mathrm{ER}=0,038 \mathrm{x}$ $\left.\mathrm{PCVZ}^{0,75} \times \mathrm{GDPCVZ}^{0,9896}\right)$, e as $\mathrm{k}_{\mathrm{f}}$ para as concentrações de EM de 2,09 e 2,42 Mcal/kg de MS, obtidas no presente trabalho por intermédio da equação que relaciona as concentrações de ELg, em função das concentrações de EM das dietas. Apenas foram utilizados os valores relativos às exigências líquidas de energia dos dados em conjunto, porque o teste de identidade de modelos, efetuado por Veloso et al. (2001), indicou não haver diferença entre os tratamentos.

As exigências de EM aumentaram, à medida que o peso corporal se elevou, o que concorda com o AFRC (1993), que estimou aumento nas exigências de EM para ganho de $1 \mathrm{~kg}$, de 79 para $95 \mathrm{MJ} / \mathrm{dia}$, com a elevação do peso vivo de 300 para $400 \mathrm{~kg}$, respectivamente.

Tabela 4 - Exigência diária de EM e ED, expressa em Mcal/dia, e exigência de NDT (kg/dia), para mantença de bovinos F1 Limousin x Nelore, em função do peso vivo (PV) ou do peso do corpo vazio (PCVZ)

Table 4 - Daily metabolizable energy (ME) and digestible energy (DE) requirements, express in Mcal/day, and TDN requirements (kg/day), for maintenance of F1 Limousin x Nellore bulls, as function of live weight (LW) or empty body weight (EBW)

\begin{tabular}{|c|c|c|c|c|}
\hline $\begin{array}{l}\mathrm{PV}(\mathrm{kg}) \\
L W\end{array}$ & $\begin{array}{c}\mathrm{PCVZ}(\mathrm{kg}) \\
E B W(\mathrm{~kg})\end{array}$ & $\begin{array}{c}\mathrm{EM}(\mathrm{Mcal} / \mathrm{dia}) \\
M E(M c a l / d)\end{array}$ & $\begin{array}{c}\mathrm{ED}(\mathrm{Mcal} / \mathrm{dia}) \\
D E(M c a l / d)\end{array}$ & $\begin{array}{c}\operatorname{NDT}(\mathrm{kg} / \mathrm{dia}) \\
T D N(\mathrm{~kg} / \mathrm{d})\end{array}$ \\
\hline 300 & 269,04 & 7,50 & 9,15 & 2,07 \\
\hline 350 & 313,89 & 8,42 & 10,27 & 2,33 \\
\hline 400 & 358,73 & 9,31 & 11,35 & 2,57 \\
\hline 450 & 403,57 & 10,17 & 12,40 & 2,81 \\
\hline 500 & 448,41 & 11,00 & 13,42 & 3,04 \\
\hline
\end{tabular}

Tabela 5 - Estimativa das exigências de ELg (Mcal/kg GPCVZ), de EM (Mcal/kg GPVJ) e de NDT (kg/kg GPVJ), em função das concentrações de EM da dieta (Mcal/kg de MS) e das respectivas eficiências de utilização da energia metabolizável para ganho de peso $\left(\mathrm{k}_{\mathrm{f}}\right)$, em \%, de bovinos F1 Limousin x Nelore, para diferentes pesos vivo (PV) e de corpo vazio (PCVZ)

Table 5 - Estimate of net energy requirement for weight gain (NEg), in Mcal/kg of empty body weight gain (EBWG), of metabolizable energy (ME), in Mcal/kg SBWG, and of total digestible nutrients (TDN), in $\mathrm{kg} / \mathrm{kg}$ SBWG, in function of dietary ME concentrations (Mcal/kg DM), and of respective utilization efficiencies of metabolizable energy for weight gain, in \%, of F1 Limousin $x$ Nellore bulls, according to different live weight (LW) or empty body weight (EBW)

\begin{tabular}{|c|c|c|c|c|c|c|c|}
\hline \multirow{5}{*}{$\begin{array}{l}\mathrm{PV}(\mathrm{kg}) \\
L W(k g)\end{array}$} & \multirow{5}{*}{$\begin{array}{c}\mathrm{PCVZ}(\mathrm{kg}) \\
E B W(\mathrm{~kg})\end{array}$} & \multicolumn{6}{|c|}{$\begin{array}{l}\text { EM da dieta } \\
\text { Dietary } M E\end{array}$} \\
\hline & & \multicolumn{2}{|c|}{$2,09\left(\mathrm{k}_{\mathrm{f}}=0,36\right)$} & & & \multicolumn{2}{|c|}{$2,42\left(\mathrm{k}_{\mathrm{f}}=0,45\right)$} \\
\hline & & \multicolumn{6}{|c|}{$\begin{array}{l}\text { Exigências } \\
\text { Requirements }\end{array}$} \\
\hline & & ELg & $\mathrm{EM}$ & NDT & ELg & $\mathrm{EM}$ & NDT \\
\hline & & $\mathrm{NFg}$ & $M E$ & $T D N$ & $\mathrm{NFg}$ & $M E$ & $T D N$ \\
\hline 300 & 269,04 & 2,53 & 7,17 & 1,98 & 2,53 & 5,73 & 1,59 \\
\hline 350 & 313,89 & 2,84 & 8,04 & 2,22 & 2,84 & 6,43 & 1,78 \\
\hline 400 & 358,73 & 3,14 & 8,89 & 2,46 & 3,14 & 7,11 & 1,97 \\
\hline 450 & 403,57 & 3,43 & 9,71 & 2,69 & 3,43 & 7,77 & 2,15 \\
\hline 500 & 448,41 & 3,72 & 10,51 & 2,91 & 3,72 & 8,41 & 2,33 \\
\hline
\end{tabular}

R. Bras. Zootec., v.31, n.3, p.1286-1293, 2002 
Tabela 6 - Exigências nutricionais de energia e proteína para bovinos F1 Limousin x Nelore não-castrados, com diferentes ganhos médios diários (GMD) de peso vivo

Table 6 - Energy and protein nutritional requirements for F1 Limousin x Nellore bulls, according to different average daily live weight gain (ADG)

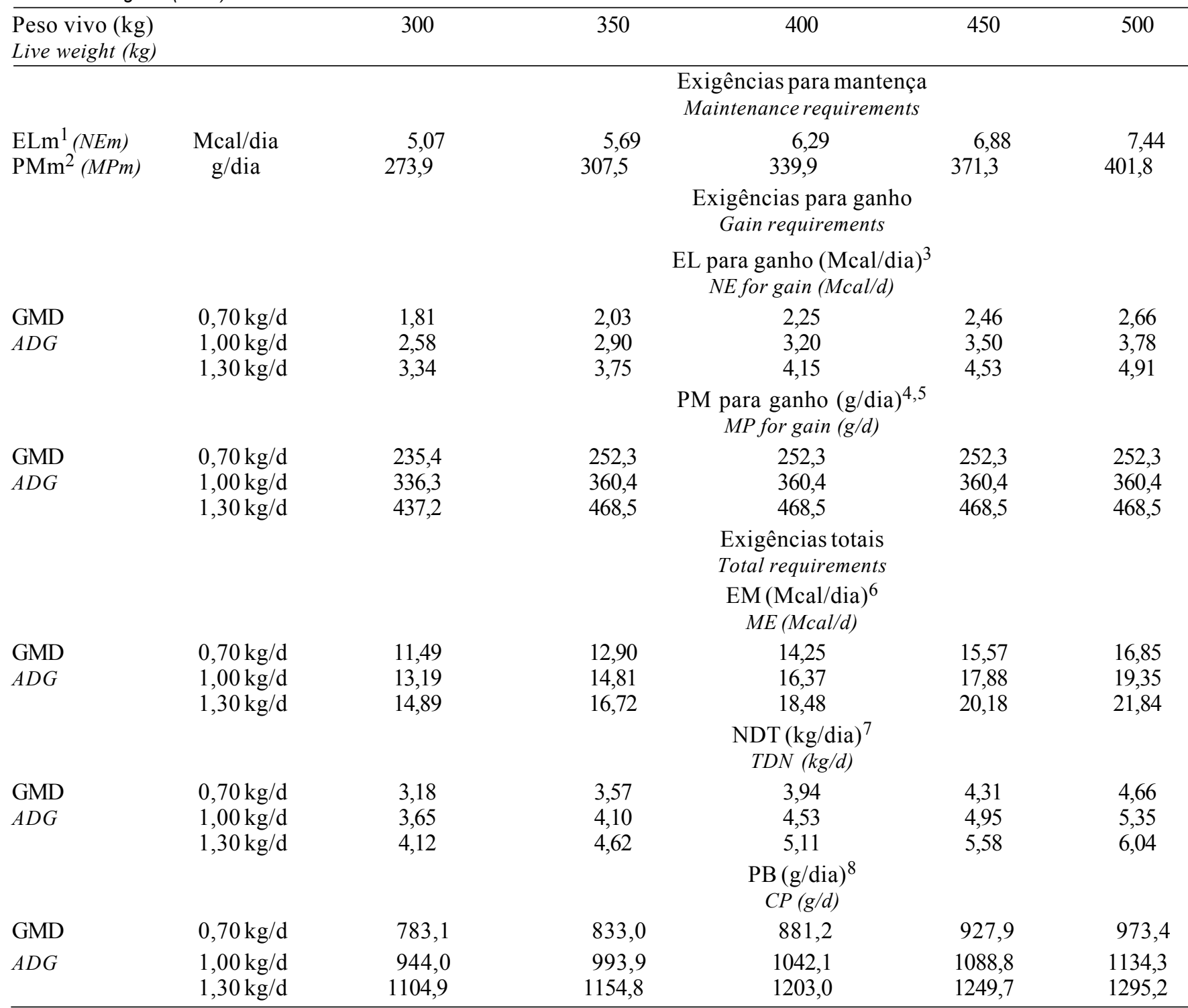

${ }^{1} \mathrm{ELm}=76,36 \mathrm{kcal} / \mathrm{PCVZ} 0,75$ (Veloso et al., 2002).

$2 \mathrm{PMm}=3,8 \mathrm{~g} / \mathrm{kg}^{0,75}$ (NRC, 1996).

${ }^{3} \mathrm{ELg}=0,038134 \times \mathrm{PCVZ}^{0,75} \times \mathrm{GDPCVZ}^{0,989638}$ (Veloso et al., 2002).

${ }^{4} \mathrm{PR}=174,14524 \times \mathrm{GMD}$ (Veloso et al., 2002).

${ }^{5} \mathrm{PMg}=\mathrm{PR} / 0,492$, para PCVZ $>300 \mathrm{~kg}$ ou PR/(83,4 - (0,114 x PCVZ)) para PCVZ $\leq 300 \mathrm{~kg}(\mathrm{NRC}, 1996)$.

${ }_{7}^{6} k_{m}=0,68$ e $k_{f}=0,45$ (dieta com 2,42 Mcal $/ \mathrm{kg} \mathrm{MS}$ ).

${ }^{7} \mathrm{NDT}=\mathrm{EM} / 0,82 / 4,409$ (NRC, 1996).

${ }^{8} \mathrm{~PB}=\mathrm{PM}$ total $/ 0,672$. O fator 0,672, de utilização da PB, corresponde a uma dieta com $80 \%$ de degradabilidade ruminal (NRC, 1996). The .672 factor, for CP utilization, correspond to a diet with $80 \%$ ruminal degradability (NRC, 1996).

As exigências líquidas para ganho de PCVZ foram convertidas para ganho de PV por meio da multiplicação pelo fator 1,02, segundo Veloso et al. (2002).

As exigências líquidas e totais para diferentes PV e taxas de ganho de PV são apresentadas na Tabela 6. As exigências totais de EM (mantença + ganho de $1 \mathrm{~kg}$ de PV) e de NDT de um animal pesando $400 \mathrm{~kg}$ de $\mathrm{PV}$ foram de $16,37 \mathrm{Mcal} / \mathrm{dia}$ e $4,53 \mathrm{~kg} /$ dia, respectivamente. A exigência de NDT foi inferior à recomendada pelo NRC (1984) para um bovino não-castrado de tamanho corporal médio, com PV de $400 \mathrm{~kg}$, ganhando cerca de $1 \mathrm{~kg} / \mathrm{dia}$, que é de $6,0 \mathrm{~kg} / \mathrm{dia}$. Segundo Minish \& Fox (1982), citados por Barbosa (1995), são consideradas raças de bovinos de tamanho corporal médio aquelas nas quais os machos não-castrados atingem acabamento para o abate (aproximadamente $24 \%$ de gordura na carcaça) com PV médio de $490 \mathrm{~kg}$. 


\section{Conclusões}

A eficiência de utilização da EM para mantença $(\mathrm{km})$ calculada foi de 0,68 , superior à recomendada pelo NRC (1996), e a eficiência de utilização da EM para ganho (kf) estimada foi de 0,$37 ; 0,36 ; 0,41 ; 0,45$; e 0,39 , respectivamente, para as concentrações de EM da dieta de 1,$93 ; 2,09 ; 2,28 ; 2,42 ;$ e $2,70 \mathrm{Mcal} / \mathrm{kg}$ de MS, obtidas para os níveis de $25 ; 37,5 ; 50 ; 62,5 ;$ e 75\% de concentrado.

As exigências totais de EM, ED e NDT encontradas neste experimento, para animais F1 Limousin x Nelore, foram inferiores às recomendadas pelo NRC (1996).

A eficiência de utilização da EM para ganho de peso de bovinos F1 Limousin x Nelore não-castrados, recebendodietas com $25 ; 37,5 ; 50 ; 62,5 ; \mathrm{e} 75 \%$ de concentrado, pode ser estimada, respectivamente, pelas equações:

$$
\begin{aligned}
& \hat{Y}=-2,47623+0,366422 \mathrm{X}, \mathrm{r}^{2}=0,79 ; \hat{Y}=-2,37030 \\
& +0,357893 \mathrm{X}, \mathrm{r}^{2}=0,89 ; \\
& \hat{Y}=-2,79704+0,413828 \mathrm{X}, \mathrm{r}^{2}=0,96 ; \hat{Y}=-3,00176 \\
& +0,448773 \mathrm{X}, \mathrm{r}^{2}=0,91 \mathrm{e} \hat{Y}=-2,69502+0,393569 \mathrm{X}, \mathrm{r}^{2}=0,96
\end{aligned}
$$

\section{Literatura Citada}

AGRICULTURAL AND FOOD RESEARCH COUNCIL AFRC. Energy and protein requirements of ruminants. Wallingford: CAB International, 1993. 159p.

AGRICULTURAL RESEARCH COUNCIL - ARC. The nutrient requirements of ruminants livestock. London: CAB International, 1980. 351p.

BOIN, C. Alguns dados sobre exigências de energia e de proteína de zebuínos. In: PEREIRA, J.C. (Ed.). SIMPÓSIO INTERNACIONAL SOBRE EXIGÊNCIAS NUTRICIONAIS DE RUMINANTES, 1995, Viçosa, MG. Anais... Viçosa, MG: Universidade Federal de Viçosa, 1995. p.457-466.

CARDOSO, R.C.; VALADARES FILHO, S.C.; SILVA, J.F.C. et al. Consumo e digestibilidades aparentes totais e parciais de rações contendo diferentes níveis de concentrado, em novilhos F1 Limousin x Nelore. Revista Brasileira de Zootecnia, v.29, n.6, p.1832-1843, 2000.

DIAS, H.L.C.; VALADARES FILHO, S.C.; SILVA, J.F.C. et al. Consumo e digestões totais e parciais em novilhos F1 Limousin $\mathrm{x}$ Nelore alimentados com dietas contendo cinco níveis de concentrado. Revista Brasileira de Zootecnia, v.29, n.2, p.545-554, 2000.

FERREIRA, M.A.; VALADARES FILHO, S.C.; SILVA, J.F.C. et al. Eficiência de utilização da energia metabolizável para ganho de peso e exigências de energia metabolizável e nutrientes digestíveis totais de bovinos F1 Simental x Nelore. Revista Brasileira de Zootecnia, v.28, n.2, p.368-373, 1999.

FERRELL, C.L. Energy metabolism. In: CHURCH, D.C. (Ed.) The ruminant animal: digestive physiology and nutrition. Englewood Cliffs: Prentice Hall, 1988. p.250-268.

FERRELL, C.L.; JENKINS, T.G. Body composition and energy utilization by steers of diverse genotypes fed a highconcentrate diet during the finishing period: I. Angus, Belgian Blue, Hereford, and Piedmontese Sires. Journal of Animal Science, v.76, p.637-646, 1998a.

FERRELL, C.L.; JENKINS, T.G. Body composition and energy utilization by steers of diverse genotypes fed a highconcentrate diet during the finishing period: II. Angus, Boran, Brahman, Hereford, and Tuli sires. Journal of Animal Science, v.76, p.647-657, 1998b.

FONTES, C.A.A. Composição corporal, exigências líquidas de nutrientes para ganho de peso e desempenho produtivo de animais zebuínos e mestiços europeu-zebu. Resultados experimentais. In: SIMPÓSIO INTERNACIONAL SOBRE EXIGÊNCIAS NUTRICIONAIS DE RUMINANTES, 1995, Viçosa. Anais... Viçosa, MG: Universidade Federal de Viçosa, MG, 1995. p.419-455.

GARRETT, W.N. Energy utilization by growing cattle as determined in 72 comparative slaughter experiments. In: SYMPOSIUMOF ENERGY METABOLISM, 8., 1980, Cambridge.Proceedings... London: EAAP Publ. n.28, 1980a. p.3-7.

GARRETT, W.N. Factors influencing energetic efficiency of beef production. Journal of Animal Science, v.51, n.6, p.1434-1440, 1980b.

HALL, M.B. Recent advances in non-NDF carbohydrates for the nutrition of lactating cows. In: SIMPÓSIO INTERNACIONAL EM BOVINOCULTURA DE LEITE: NOVOS CONCEITOS EM NUTRIÇÃO, 2., 2001, Lavras. Proceedings... Lavras: Universidade Federal de Lavras, 2001. p.139-148.

HARRIS, L.F. Nutrition research technique for domestic and wild animal. v.1. Utah: Logan, 1970. (paginação descontínua)

LANA, R.P. Composição corporal e exigências de energia, proteína e macroelementos minerais ( $\mathrm{Ca}, \mathrm{P}, \mathrm{Mg}$, Na e $\mathrm{K}$ ) de novilhos de 5 grupos raciais, em confinamento. Viçosa, MG: Universidade Federal de Viçosa, 1991. 134p. Dissertação (Mestrado em Zootecnia)-Universidade Federal de Viçosa, 1991.

NATIONAL RESEARCH COUNCIL - NRC. Nutrient requirements of beef cattle. 6.ed. Washington, D.C.: National Academy Press, 1984. 90p.

NATIONAL RESEARCH COUNCIL - NRC. Nutrient requirements of beef cattle. 7.ed. Washington, D.C.: National Academy Press, 1996. 242p.

RATTRAY, P.D.; JOYCE, J.P. Utilization of metabolizable energy for fat and protein deposition in sheep. Journal of Agriculture, v.19, n.2, p.299-305, 1976.

SILVA, D.J. Análise de alimentos (métodos químicos e biológicos). Viçosa, MG: Universidade Federal de Viçosa, 1990. 165p.

SILVA, F.F.; VALADARES FILHO, S.C.; ÍTAVO, L.C.V. et al. Eficiência de utilização da energia metabolizável para mantença e ganho de peso de bovinos Nelore não-castrados. In: REUNIÃO ANUAL DA SOCIEDADE BRASILEIRA DE ZOOTECNIA, 38., 2001, Piracicaba. Anais... Piracicaba: Sociedade Brasileira de Zootecnia, 2001. p.934-936.

SILVA, J.F.; LEÃO, M.I. Fundamentos de nutrição dos ruminantes. Piracicaba: Livroceres, 1979. 380p.

VALADARES FILHO, S.C. Nutrição de bovinos de corte: Problemas e perspectivas. In: REUNIÃO ANUAL DA SOCIEDADE BRASILEIRA DE ZOOTECNIA, 32., 1995, Brasília. Anais... Brasília: Sociedade Brasileira de Zootecnia, 1995. p.156-161.

Van SOEST, P.J. Nutritional ecology of the ruminant. 2.ed. Ithaca: Cornell University Press, 1994. 476p.

VELOSO, C.M.; VALADARES FILHO, S.C.; GESUALDI Jr., A. et al. Composição corporal e exigências energéticas e protéicas de bovinos F1 Limousin x Nelore, não-castrados, alimentados com rações contendo diferentes níveis de concentrado. Revista Brasileira de Zootecnia, v.31, n.3, p.1273-1285, 2002.

Recebido em: 29/05/01 Aceito em: 07/05/02

R. Bras. Zootec., v.31, n.3, p.1286-1293, 2002 